\title{
Experimental investigation on the slip between oil and water in horizontal pipes
}

\author{
Jing-yu Xu* ${ }^{*}$, Ying-xiang Wu, Fei-fei Feng, Ying Chang, Dong-hui Li \\ Division of Engineering Sciences, Institute of Mechanics, Chinese Academy of Sciences, Beijing 100190, China
}

\section{A R T I C L E I N F O}

\section{Article history:}

Received 29 May 2008

Received in revised form 25 July 2008

Accepted 26 July 2008

\section{Keywords:}

Oil-water flow

Slip velocity

Horizontal pipes

\begin{abstract}
A B S T R A C T
This work is devoted to study of the slip phenomenon between phases in water-oil two-phase flow in horizontal pipes. The emphasis is placed on the effects of input fluids flow rates, pipe diameter and viscosities of oil phase on the slip. Experiments were conducted to measure the holdup in two horizontal pipes with $0.05 \mathrm{~m}$ diameter and $0.025 \mathrm{~m}$ diameter, respectively, using two different viscosities of white oil and tap water as liquid phases. Results showed that the ratios of in situ oil to water velocity at the pipe of small diameter are higher than those at the pipe of big diameter when having same input flow rates. At low input water flow rate, there is a large deviation on the holdup between two flow systems with different oil viscosities and the deviation becomes gradually smaller with further increased input water flow rate.
\end{abstract}

(c) 2008 Elsevier Inc. All rights reserved.

\section{Introduction}

Flows of oil and water two-phase are encountered in a diverse range of processes and equipment. For example, in the oil industry, mixtures of oil and water are transported in pipes over long distances. In order to estimate accurately the holdup, it is necessary to know the actual flow pattern under the specific flow conditions. Several flow pattern maps have been observed depending upon the physical properties and input fluxes of the two phases, and the size and orientation of pipe [1-5]. According to the classification by [5-8], the main flow regimes in a horizontal pipe can generally be classified into the following two categories:

\subsection{Segregated flow}

Where the two-fluids flow in separate layers according to their different densities (ST or ST\&MI flows). Furthermore, at certain conditions, for high viscosity oil and water flow, one phase can occupy the core of the pipe with the other flowing in the annulus around it (AN flow) [9-12].

\subsection{Dispersed flow}

Where one fluid is continuous and the other is in the form of drops dispersed in it $(D o / w \& w, D w / 0 \& 0, D o / w \& D w / o, o / w$ or $w / 0$ flows).

Accurate prediction of holdup in oil-water flow is important in many engineering applications. However, despite of their importance, liquid-liquid flows have not been explored to the same

\footnotetext{
* Corresponding author. Tel.: +86 108254 4173; fax: +86 1062561284

E-mail address: jinyu.xu@gmail.com (J.-y. Xu).
}

extent as gas-liquid flows. Due to the difference in density between the two-fluids and their holdups, there is a slip velocity between the phases. Unlike the gas-liquid flow, very little information focuses on this case between oil and water.

The slip phenomenon can be expressed by the ratio between the average in situ velocities of the two-phases. It is given in terms of the velocity ratio, $S$, defined as the ratio of in situ oil to water velocity, which can be expressed as follows:

$S=\frac{\beta_{\mathrm{o}} / \beta_{\mathrm{w}}}{\varepsilon_{\mathrm{o}} / \varepsilon_{\mathrm{w}}}$

where $\beta_{\mathrm{o}}$ and $\beta_{\mathrm{w}}$ are the input volume fractions of oil and water respectively, averaged over the pipe cross-section, and $\varepsilon_{\mathrm{o}}$ and $\varepsilon_{\mathrm{W}}$ are the in situ volume fractions of oil and water, respectively, averaged over the pipe cross-section. Accordingly, $S$ is greater than 1 when oil is the faster flowing phase, and conversely $S$ is less than 1 when water is the faster flowing phase.

Angeli and Hewitt [8] measured $S$ in an acrylic pipe with $24 \mathrm{~mm}$ diameter. Results showed that in most cases $S$ was less than unity when the majority of the flow regimes were in segregated flow. They used the Lockhart-Martinelli parameter $(\chi)$ to predict in situ volume fraction $\varepsilon_{0}$ and gave the following correlation by the multiple regression analysis of the experimental data:

$\ln \left(\varepsilon_{0}\right)=0.4134 \ln (\chi)-0.6004$

It can be seen from the equation that, although it is noteworthy, $\varepsilon_{0}$ should be bigger than unity when $\chi>4.27$, which does not have a physical sense. Lovick and Angeli [13] performed the experimental work to study the dual continuous horizontal flow (ST\&MI flow) in a $38 \mathrm{~mm}$ diameter using water and oil $(6 \mathrm{mPa} \cdot \mathrm{s}$ viscosity and $828 \mathrm{~kg} / \mathrm{m}^{3}$ density) as test fluids. The experimental data showed that $S$ increased during dual continuous flow from below 1 to above 


\begin{tabular}{llll}
\multicolumn{2}{l}{ Nomenclature } & & \\
& & & \\
$Q_{w}$ & water flow rate $\left(\mathrm{m}^{3} / \mathrm{h}\right)$ & \multicolumn{2}{l}{ Greek letters } \\
$Q_{0}$ & oil flow rate $\left(\mathrm{m}^{3} / \mathrm{h}\right)$ & $\rho$ & density of fluid $\left(\mathrm{kg} / \mathrm{m}^{3}\right)$ \\
$u_{\mathrm{so}}$ & superficial oil velocity $(\mathrm{m} / \mathrm{s})$ & $\sigma$ & surface tension $(\mathrm{N} / \mathrm{m})$ \\
$u_{\mathrm{sw}}$ & superficial water velocity $(\mathrm{m} / \mathrm{s})$ & $\mu$ & viscosity $(\mathrm{Pa} \cdot \mathrm{s})$ \\
$u_{\mathrm{o}}$ & average in situ oil velocity $(\mathrm{m} / \mathrm{s})$ & $\varepsilon_{0}$ & in situ volume fractions of oil \\
$q$ & the ratio of input water to oil volume fraction (dimen- & $\beta_{0}$ & input volume fractions of oil (dimensionless) \\
& sionless) & $\chi$ & Lockhart-Martinelli parameter (dimensionless) \\
$D$ & pipe diameter $(\mathrm{m})$ & &
\end{tabular}

1 as the input oil fraction increased. At high input oil fractions, however, $S$ decreased again to values below 1 as the mixture velocity increased.

These studies above focuses on the effect of input fluids flow rate on the slip. A survey of the past literature shows that no experiment, to the best of the authors' knowledge, has been reported till date to investigate the slip between oil and water using different oil phases at a fixed system. In liquid-liquid horizontal flows, available data were usually measured under the conditions that the pipe diameter and fluid viscosity are fixed, especially for a low viscosity oil and water flow. Fig. 1 shows $S$ against the ratio of input water to oil volume fraction $(q)$ in the available literature

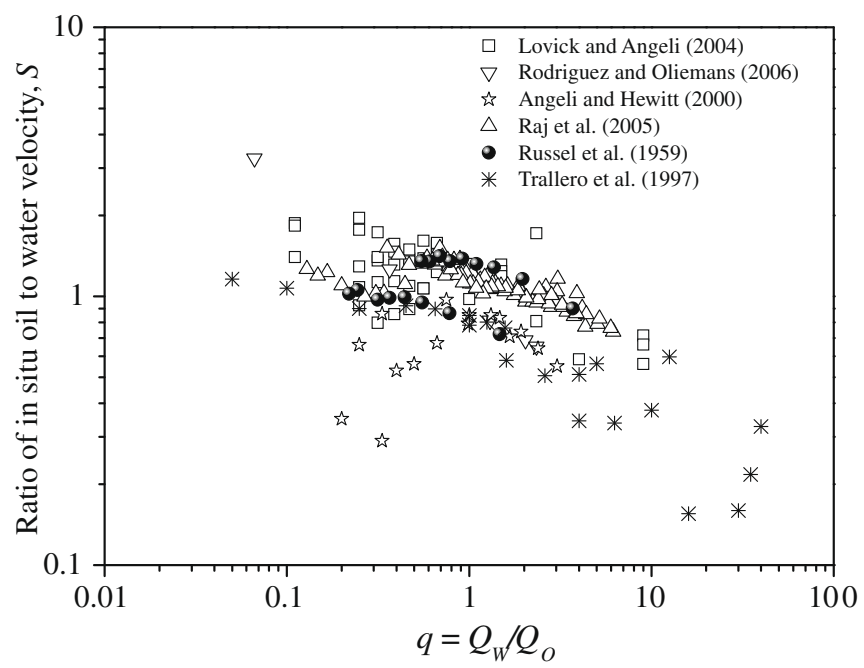

Fig. 1. Ratio of in situ oil to water velocity versus ratio of input water to oil volume fraction in the literature for segregated flow.
$[2,8,13-16]$ for the same flow pattern (segregated flow). These data indicate, in general, that the values of $S$ decrease with increasing $q$. However, due to the different experimental systems used, it is difficulty to observe the effects of the pipe diameter and the properties of the fluids on the slip using these results. Therefore, the objective in this work is to study in depth the effects of input fluid flow rates, pipe diameter and fluid properties on the slip in horizontal pipes. Furthermore, two different viscosities of white oil have been used here to study the average in situ oil fraction according to different flow patterns.

\section{Experimental set-up and procedure}

The experiments reported below were carried out on the multiphase flow facilities at Institute of Mechanics, Chinese Academy of Sciences. A schematic diagram of the experimental system was shown in Fig. 2. All experiments were conducted using white oil and water at room-temperature and atmospheric outlet pressure. Measurements were made for water flow rates from 0.5 to $12.5 \mathrm{~m}^{3} / \mathrm{h}$ and input oil volume fractions from $3 \%$ to $94 \%$. The system consisted of a steel frame supporting a transparent Perspex pipes. Water and oil were pumped from their respective storage tanks, metered, and introduced into pipes via a T-junction. The mixture flowed along a $12 \mathrm{~m}$ long horizontal pipe from the entry point, which provided sufficient entrance length to stabilize the flow, to the test section. To examine the effect of the diameter on the flow phenomena, the test sections consisted of the two different pipes with $0.05 \mathrm{~m}$ and $0.025 \mathrm{~m}$ diameter, respectively. Four rapid closing valves (RV1-RV4) were implemented to switch the flow between the tubes for transient flow tests. For example, for flowing in a horizontal pipe with $0.05 \mathrm{~m}$ diameter, RV1 and RV2 were open and allowed the fluid to flow along the pipe with $0.05 \mathrm{~m}$ diameter while RV3 and RV4 stay closed in order to block the pipe with $0.025 \mathrm{~m}$ diameter so that it remained full in the pipe. Different flow

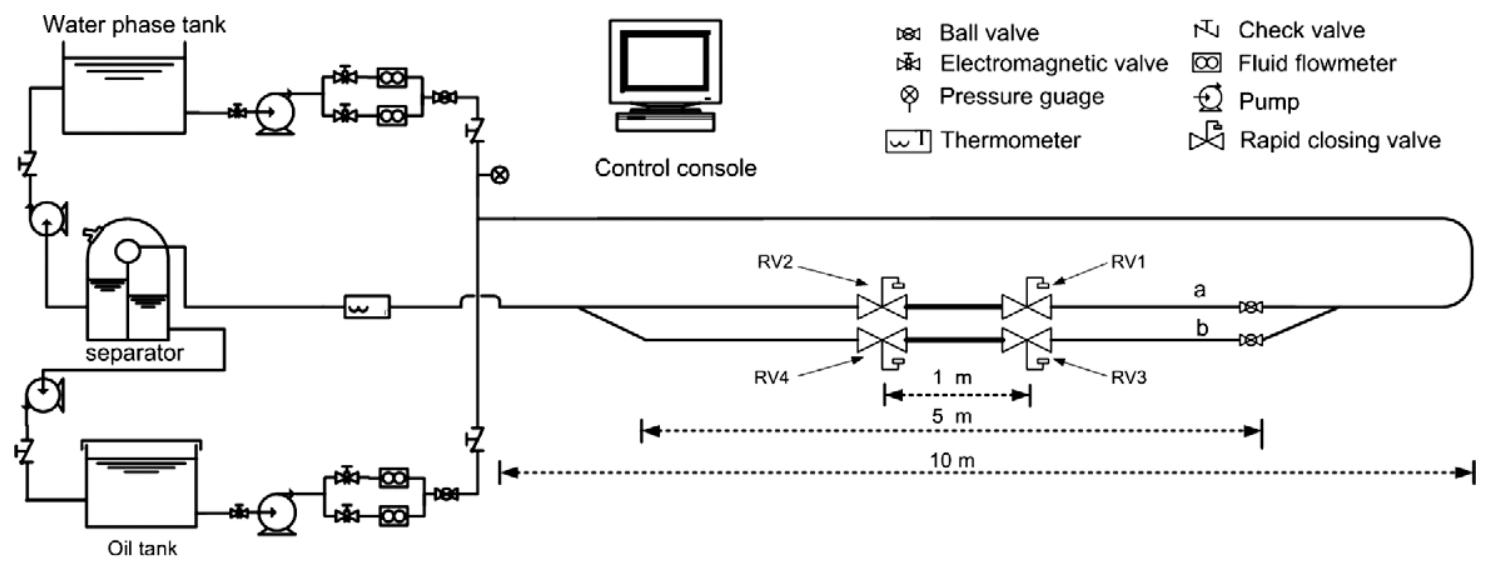

Fig. 2. Schematic of the test facility (a, $D=50 \mathrm{~mm}$; b, $D=25 \mathrm{~mm}$ ). 
Table 1

Liquid phase's properties measured at $20^{\circ} \mathrm{C}$ and $0.101 \mathrm{MPa}$

\begin{tabular}{llll}
\hline Liquid phase & Density $\left(\mathrm{kg} / \mathrm{m}^{3}\right), \rho$ & Surface tension $(\mathrm{N} / \mathrm{m}), \sigma$ & Viscosity $(\mathrm{Pa} \cdot \mathrm{s}), \mu$ \\
\hline Water & 998 & 0.0712 & 0.001 \\
White oil 1 & 860 & 0.0445 & 0.050 \\
White oil 2 & 860 & 0.0452 & 0.138
\end{tabular}

structures can be obtained through adjusting the input flow rates of water and oil by the pumps themselves. When the steady state was reached under a flow condition, the input flow fluids rates were measured. The high-speed camera recorded the continuous flow process synchronously when the camera frequency was set at $1 \mathrm{kHz}$, which was high enough to capture the details of the flow process. The holdup measurement was taken after the mixture flowing along a $4.5 \mathrm{~m}$ long horizontal pipe from the bend. The rapid closing valves system was operated three times to obtain the averaged water holdup under the flow condition. Under each flow condition, the fluctuation of mean value of the holdup among the three times is around 6.3\%. Moreover, the effect of the fluid properties on the slip was also studied using two different viscosities of white oil. The physical properties of test liquids have been listed in Table 1.

\section{Experimental results and discussions}

\subsection{Flow patterns}

The flow patterns have been observed visually as well as by photographic techniques. In the present work, the flow structures of oil-water two-phase flow are distinguished, in general, as six basic flow structures according to the definition of Trallero et al. [2] and Brauner [5]. They are: stratified flow (ST), stratified flow with mixing at the interface (ST\&MI), dispersion of oil in water and water $(D o / w \& w)$, oil in water emulsion $(o / w)$, dispersions of water in oil and oil in water $(D w / o \& D o / w)$ and water in oil emulsion $(w / o)$. Flow pattern map of Trallero et al. [2] with corresponding flowrates, showing oil-water two-phase flowing in horizontal pipes for the experiments reported in the present work, is presented in Figs. 3a and b for $0.05 \mathrm{~m}$ diameter and $0.025 \mathrm{~m}$ diameter, respectively. The experimental data were measured using the white oil $2\left(\mu_{\mathrm{o}}=138 \mathrm{mPa} \cdot \mathrm{s}\right)$ and water system. It can be seen that the map of Trallero et al., in general, can satisfactorily describe our experimental data for oil and water two-phase flowing in pipe with $0.05 \mathrm{~m}$ diameter. However, it fails to predict the flow pattern in pipe with $0.025 \mathrm{~m}$ diameter. A comparison between Fig. $2 \mathrm{a}$ and $\mathrm{b}$ shows the influence of pipe diameter on flow pattern when having the same flow rates. The main differences are that the transition from $S T \& M I$ flow to $D w / 0 \& D o / w$ flow took place under a much lower flow rate contribution of the oil phase in the $0.025 \mathrm{~m}$ diameter than that in the $0.05 \mathrm{~m}$ diameter. The reasons for the discrepancies may be that the mixture velocity in $0.025 \mathrm{~m}$ diameter is lager than that in $0.05 \mathrm{~m}$ diameter for the same input flow rates.

Based on the experimental observation, it is found that, for most of cases, Fig. 3 can also predict white oil 1 and water flow, although there are some small differences between two systems in the same flow pattern, for instance there are a more interfacial mixing layer within ST\&MI flow of white 2 and water than that within white 1 and water flow. Thus, the flow pattern for white oil 1 and water flow can be also studied using Fig. 3. Due to the fact that, for the transition between ST flow and ST\&MI flow, the onset velocities for drop formation in the interface decrease as the viscosity ratio of oil to water increases [17], it is more easy to form the interfacial mixing in water and oil $2\left(\mu_{\mathrm{o}}=138 \mathrm{mPa} \cdot \mathrm{s}\right)$ flow than that in water and oil $1\left(\mu_{\mathrm{o}}=50 \mathrm{mPa} \cdot \mathrm{s}\right)$ flow under same input conditions.
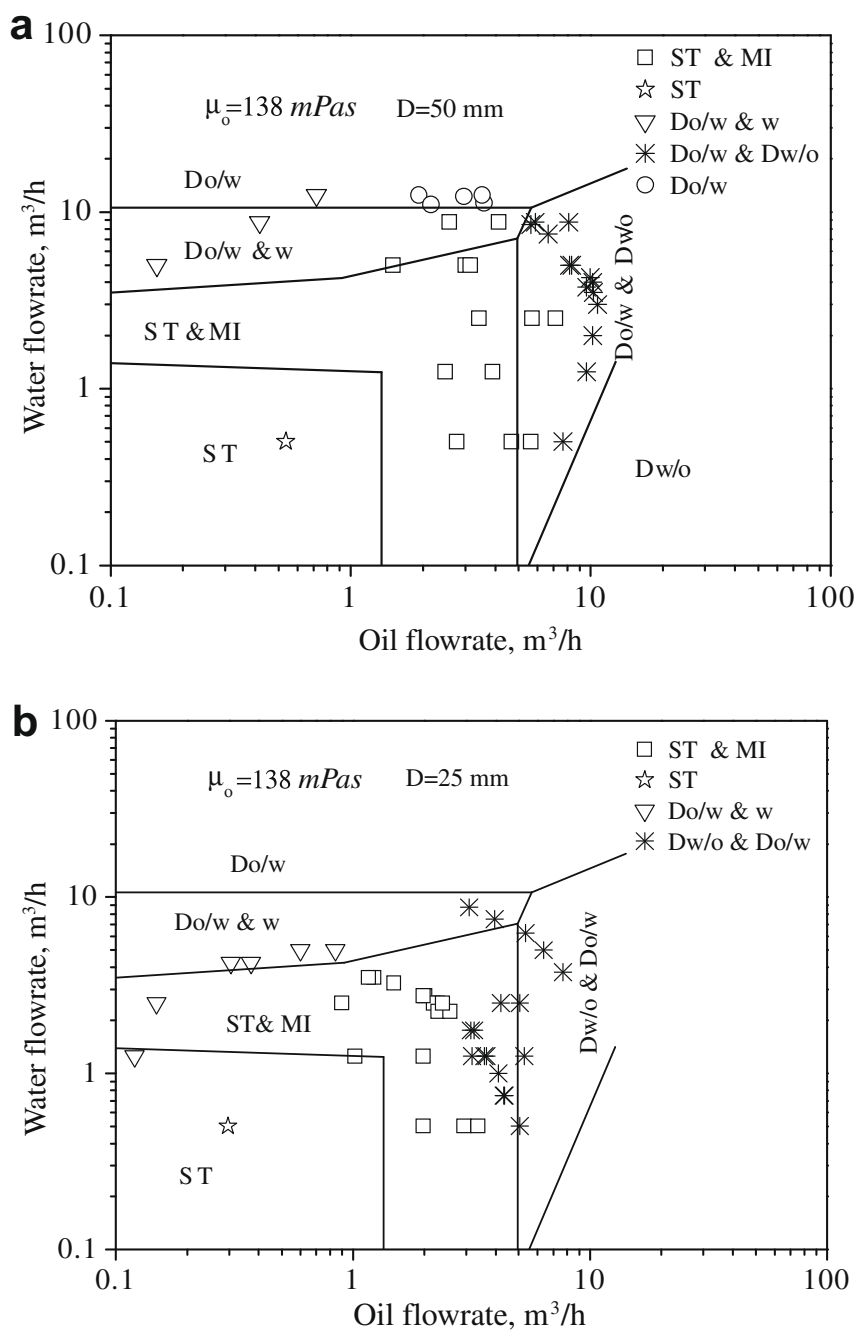

Fig. 3. Flow pattern map of Trallero et al. [2] showing inlet flow rates for the experiments reported in this work with $\mu_{\mathrm{o}}=138 \mathrm{mPa} \cdot \mathrm{s}(\mathrm{a}, D=50 \mathrm{~mm} ; \mathrm{b}, D=$ $25 \mathrm{~mm}$; the experimental conditions of Trallero et al., $\rho_{\mathrm{o}} / \rho_{\mathrm{w}}=0.85, \mu_{\mathrm{o}} / \mu_{\mathrm{w}}=29.6$, $\mathrm{D}=50 \mathrm{~mm})$.

\subsection{Effect of input fluids flow rates on the slip}

Experiments have firstly been made to investigate the influence of input oil and water flow rates $\left(Q_{0}\right.$ and $\left.Q_{w}\right)$ on the slip of the two liquids under a particular flow pattern. For this, the data has been represented at constant water flow rates. Fig. 4 depicts the effect of input fluids flow rates on the slip in horizontal pipe with the diameter of $0.05 \mathrm{~m}$ using white oil 2 and water system. In most cases, flow patterns maintain at ST\&MI flow. In general, at constant water flow rates, the ratio of in situ oil to water velocity $(S)$ increases with increasing oil flow rate. However, at high $Q_{w}$, the influence of input water flow rate appears negligible change. The values of $S$ at $Q_{w}=$ $5 \mathrm{~m}^{3} / \mathrm{h}$ are close to those at $Q_{\mathrm{w}}=8.75 \mathrm{~m}^{3} / \mathrm{h}$. Fig. 5 shows the ratio of in situ oil to water velocity against input oil fraction at different input mixture flow rates. It can be seen that, at low $\beta_{\mathrm{o}}$ value, the mixture flow rate $\left(Q_{m}\right)$ has a prominent influence on $S$ and the influence become reduced gradually with $\beta_{\mathrm{o}}$ increasing. For a given input oil fraction, with $Q_{m}$ increased, $S$ increases over the range of 0 $<\beta_{\mathrm{o}}<0.8$. A comparison of the data in the two flow rates shows that, at low $\beta_{0}$ value, the ratio of in situ oil to water velocity at dispersed flow is larger than those at segregated flow. The reasons for the discrepancies may be that, for a stratified flow with low input oil fraction, in situ water fraction $\left(\varepsilon_{\mathrm{w}}\right)$ should be less than input 


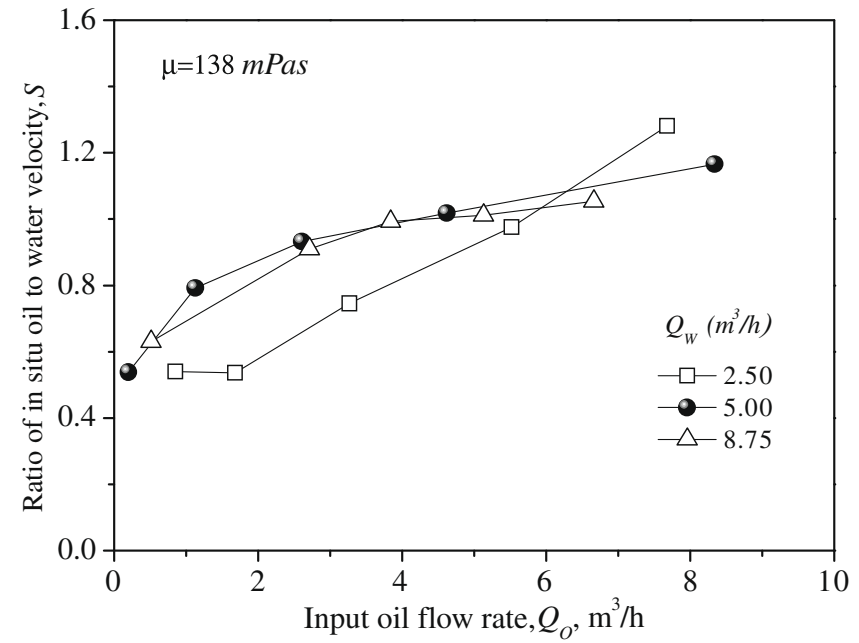

Fig. 4. The effect of input fluids flow rates on the slip in a horizontal pipe with the diameter of $0.05 \mathrm{~m}$ for white oil 2 and water flow.

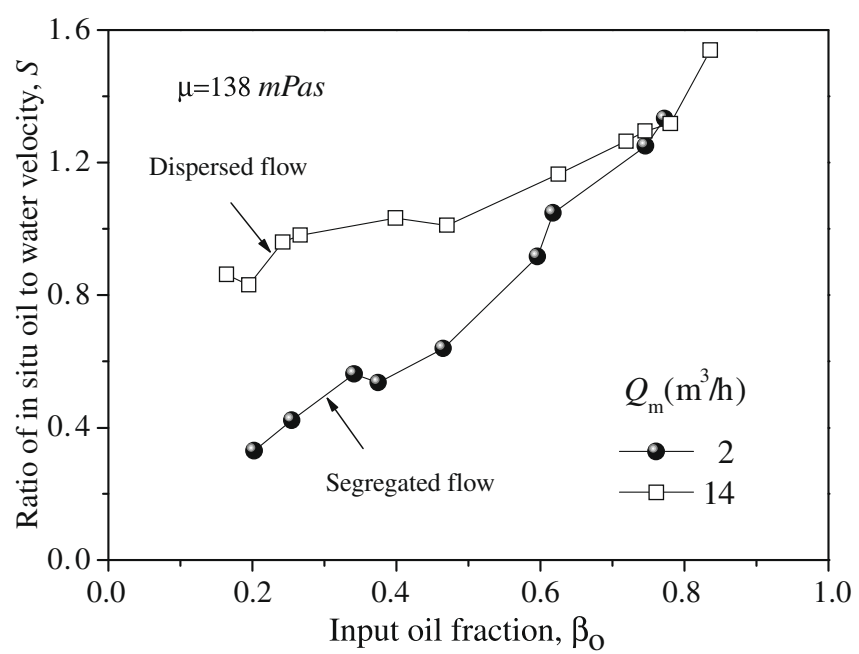

Fig. 5. The effect of mixture flow rates on the slip in a horizontal pipe with the diameter of $0.05 \mathrm{~m}$ for white oil 2 and water flow.

water fraction $\left(\beta_{\mathrm{w}}\right)$ because water is much faster than oil. Thus, $S$ should be less than 1 by analyzing the Eq. (1). However, for a dispersed flow, $S$ is close to or bigger than 1 based on the study results of Rodriguez and Oliemans [14].

\subsection{Effect of pipe diameter on the slip}

The influence of the pipe diameter on the slip of oil-water mixtures at a given water flow rate was investigated. Fig. 6 shows input fluids flow rates against the ratio of in situ oil to water velocity for white oil 2 and water flow. At a pair of given input oil and water flow rates, $S$ in $0.025 \mathrm{~m}$ diameter is higher than that in $0.05 \mathrm{~mm}$ diameter, especially for low input water flow rate. In the present work, in order to reduce the effect of flow pattern, most of experimental data were confined to SI\&MI flow. Interestingly, it is found in the figure that there is a similar tendency of change of $S$ in two pipes with increasing $Q_{0}$ when water flow rates are fixed $\left(Q_{w}=\right.$ $1.25 \mathrm{~m}^{3} / \mathrm{h}$ and $Q_{\mathrm{w}}=2.50 \mathrm{~m}^{3} / \mathrm{h}$ ). The effect of pipe diameter on the slip at constant input mixture flow rates is presented in Fig. 7. When input water flow rate is fixed at $4.50 \mathrm{~m}^{3} / \mathrm{h}$, flow patterns in $0.05 \mathrm{~m}$ diameter are segregated flow, and those in

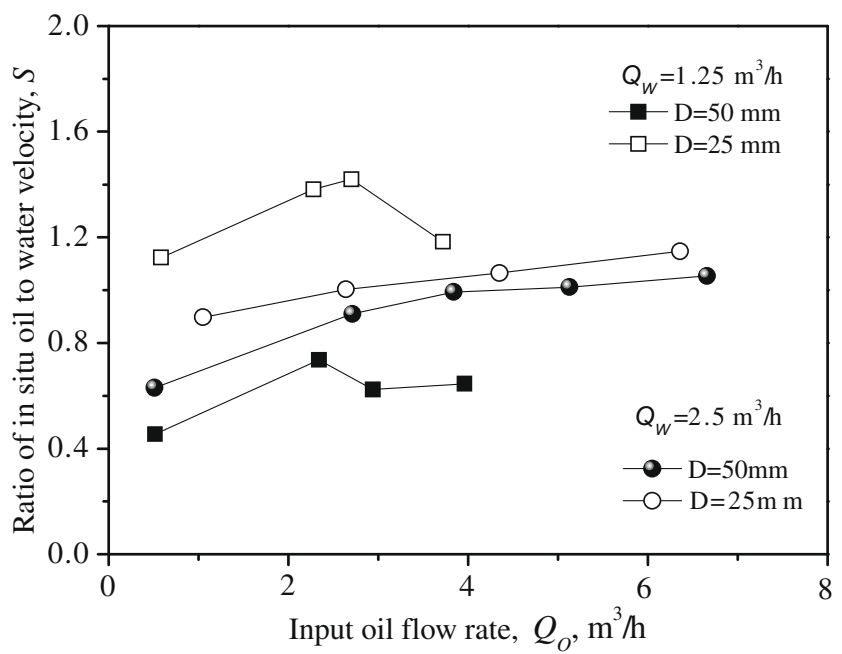

Fig. 6. The effect of pipe diameter on the slip at constant input water flow rates for white oil 2 and water flow.

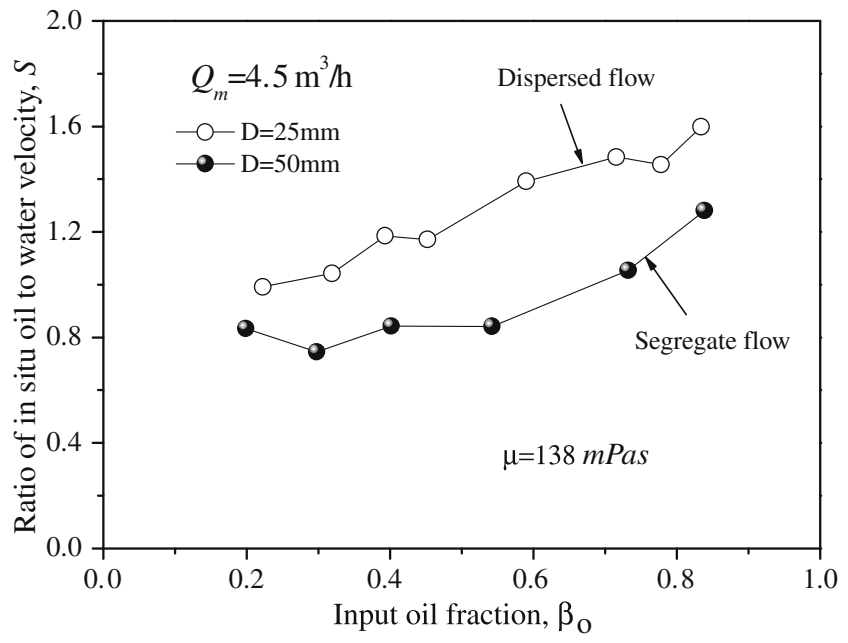

Fig. 7. The effect of pipe diameter on the slip at constant input mixture flow rates for white oil 2 and water flow.

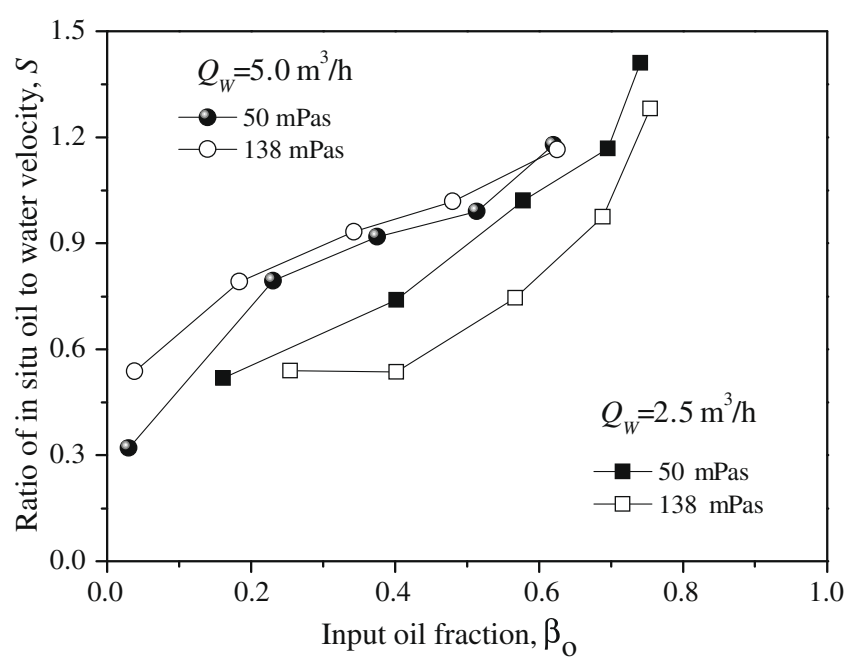

Fig. 8. The effect of oil viscosity on the slip at constant input water flow rates in a horizontal pipe with the diameter of $0.05 \mathrm{~m}$. 


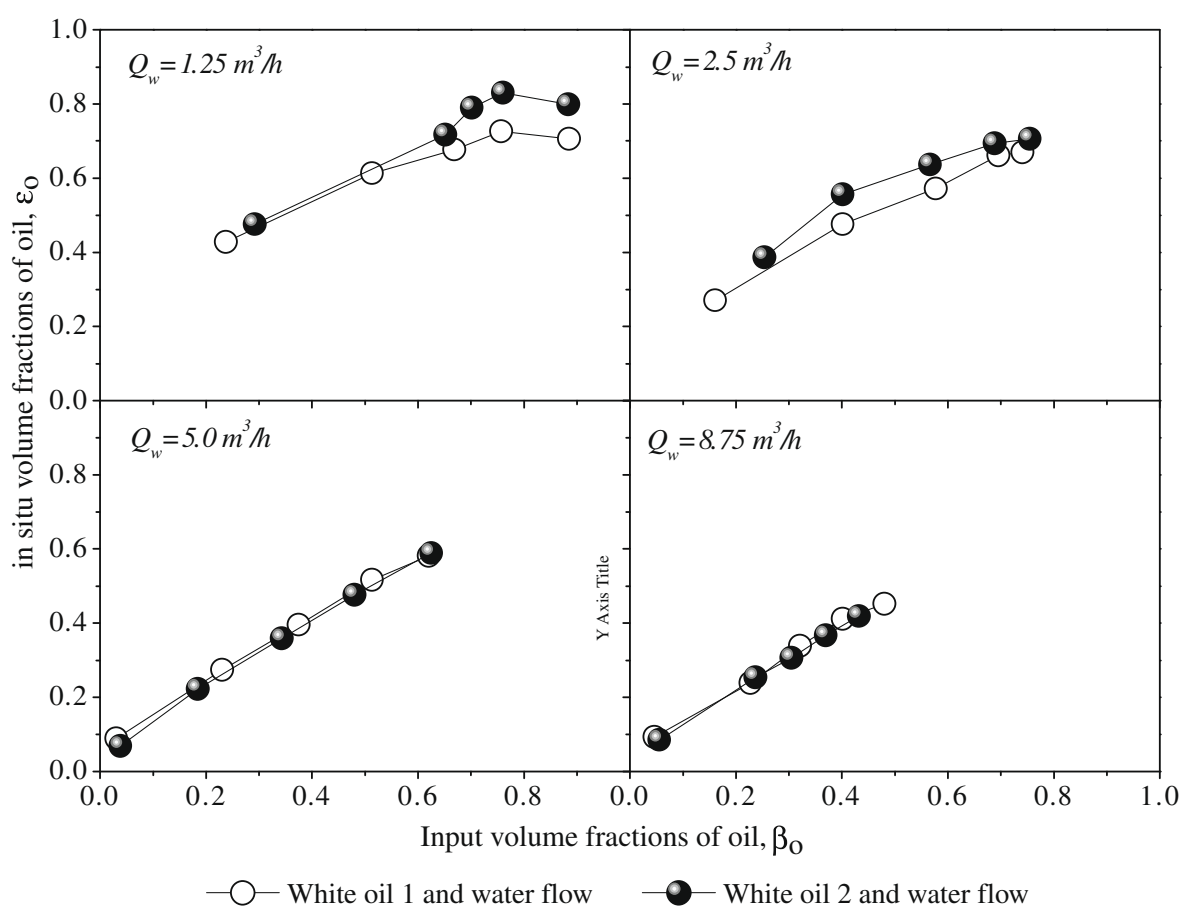

Fig. 9. In situ volume fractions of oil versus input volume fractions of oil at constant input water flow rates in a horizontal pipe with the diameter of $0.05 \mathrm{~m}$.

$0.025 \mathrm{~m}$ diameter dispersed flow. In the range of $0.2<\beta_{\mathrm{o}}<0.8$, values of $S$ at small diameter are higher than those at big diameter.

\subsection{Effect of the viscosity of oil phase on the slip}

In order to understand the effect of the viscosity of oil phase on the slip, experiments have been performed under identical fluid flow rates $\left(Q_{w}=2.5 \mathrm{~m}^{3} / \mathrm{h}\right.$ and $\left.Q_{w}=5.0 \mathrm{~m}^{3} / \mathrm{h}\right)$ but different oil viscosities of $50 \mathrm{mPa} \cdot \mathrm{s}$ (white oil 1) and $138 \mathrm{mPa} \cdot \mathrm{s}$ (white oil 2). Fig. 8 illustrates the effects of viscosity on the slip at constant input water flow rates in a horizontal pipe with the diameter of $0.05 \mathrm{~m}$. In figure, there are coincident flow patterns between two systems when having same input conditions. It can be found that $S$ at white oil 1 and water flow is higher than those at white oil 2 and water flow when $Q_{w}=2.5 \mathrm{~m}^{3} / \mathrm{h}$. Under this condition, most of flow patterns are in segregated flow. Based on the works of Ullmann et al. [18], the flow characteristics of two-fluids are dependent on two dimensionless parameters: the input flow rates ratio $(q)$ and Lockhart-Martinelli parameters $\left(\chi=\sqrt{\Delta \mathrm{d} p_{\mathrm{w}} / \Delta \mathrm{d} p_{\mathrm{o}}}\right)$, and also $\varepsilon_{\mathrm{w}}$ increases with $\chi$ increasing. In this work, under same input flow rates, $\chi$ in oil 1 and water system is higher than that in oil 2 and water system because of oil viscosity. Therefore, $\varepsilon_{\mathrm{w}}$ for oil 1 and water flow is bigger than that for oil 2 and water flow. It can be found by the Eq. (1) that, when $q$ is fixed, increasing $\varepsilon_{\mathrm{w}}$ will enlarge $S$. Thus, oil 1 and water has higher $S$ than oil 2 and water flow when two-phase flow is in segregated flow. However, with further increasing the water flow rate, the mixture flow is in dispersed flow and $S$ is close to each other as shown in Fig. 8. A detailed data is shown in Fig. 9. The graph presents in situ volume fractions of oil versus input volume fractions of oil at constant input water flow rates. It can be concluded from the experimental data, as shown in Fig. 9, that for all cases the average oil holdup, $\varepsilon_{0}$, increases with an increase at the input oil fraction and decreases with an increase at the water flow rate. However, Fig. 9 also reveals that there is a large deviation on the holdup between white oil 1/water flow and white oil 2/water flow when the water flow rate maintains values of $Q_{w}=1.25 \mathrm{~m}^{3} / \mathrm{h}$ and $2.50 \mathrm{~m}^{3} / \mathrm{h}$, respectively, and then the deviation becomes gradually smaller with increased input water flow rate. For high water flow rate $\left(Q_{w}=5.0 \mathrm{~m}^{3} / \mathrm{h}\right.$ and $Q_{w}=$ $8.75 \mathrm{~m}^{3} / \mathrm{h}$ in this work), we may see that the holdup between two systems is almost equal, namely the effects of viscosity on the slip at high input water flow rates is negligible.

\section{Conclusions}

An experimental study of oil and water flow through the horizontal pipes has been conducted. Special attention is given to study of slip between two phases. The effects of input fluids flow rates, pipe diameter and viscosities of oil phase on the slip have been observed experimentally. The work reveals that, at low $\beta_{\mathrm{o}}$ value, the ratio of in situ oil to water velocity at dispersed flow is larger than those at segregated flow. The ratios of in situ oil to water velocity at the pipe of small diameter are higher than those at the pipe of big diameter under same input flow rates. At low input water flow rate, there is a large deviation on the holdup between two flow systems with different oil viscosities and the deviation becomes gradually smaller with further increased input water flow rate.

\section{Acknowledgments}

The authors gratefully acknowledge that the work described here was financially supported by both the National Natural Science Foundation of China (Grant No. 10572143) and the Key Project of "Eleventh Five-Year Plan" of the Chinese Academy of Sciences (Grant No. KJCX2-YW-L02).

\section{References}

[1] J.L. Trallero, Oil-Water Flow Patterns in Horizontal Pipes, PhD Dissertation, The University of Tulsa, 1995.

[2] J.L. Trallero, C. Sarica, J.P. Brill, A study of oil/water flow patterns in horizontal pipes, SPE Production and Facilities August (1997) 165-172.

[3] N. Brauner, D.M. Maron, Flow pattern transitions in two-phase liquid-liquid flow in horizontal tubes, International Journal of Multiphase Flow 18 (1992) $123-140$. 
[4] M. Nädler, D. Mewes, Flow induced emulsification in the flow of two immiscible liquids in horizontal pipes, International Journal of Multiphase Flow 23 (1997) 55-68.

[5] N. Brauner, Liquid-liquid two-phase flow, in: G.F. Hewitt (Ed.), Heat Exchanger Design Update, Bell house Inc., New York, 1998, pp. 1-40. Chapter 2.3.5.

[6] J.Y.-L. Lum, J. Lovick, P. Angeli, Low inclination oil-water flows, The Canadian Journal of Chemical Engineering 82 (2004) 303-315.

[7] J.Y.-L. Lum, T. Al-Wahaibi, P. Angeli, Upward and downward inclination oilwater flows, International Journal of Multiphase Flow 32 (2006) 413-435.

[8] P. Angeli, G.F. Hewitt, Flow structure in horizontal oil-water flow, International Journal of Multiphase Flow 26 (2000) 1117-1140.

[9] G. Ooms, A. Segal, A.J. vanderWees, R. Meerhoff, R.V.A. Oliemans, A theoretical model for core-annular flow of a very viscous oil core and a water annulus through a horizontal pipe, International Journal of Multiphase Flow 10 (1983) 41-60.

[10] R.V.A. Oliemans, G. Ooms, H.L. Wu, A. Duijvestijn, Core-annular oil/water flow: the turbulent-lubricating-film model and measurements in a $5 \mathrm{~cm}$ pipe loop, International Journal of Multiphase Flow 13 (1987) 23-31.

[11] M. Arney, R. Bai, E. Guevara, D.D. Joseph, K. Liu, Friction factor and holdup studies for lubricated pipelining-I. Experiments and correlations, International Journal of Multiphase Flow 19 (1993) 1061-1076.
[12] A. Huang, C. Christodoulou, D.D. Joseph, Friction factor and holdup studies for lubricated pipelining-II Laminar and $k \varepsilon$ models of eccentric core flow, International Journal Multiphase Flow 20 (1994) 481-494.

[13] J. Lovick, P. Angeli, Experimental studies on the dual continuous flow pattern in oil-water flows, International Journal of Multiphase Flow 30 (2004) 139157.

[14] O.M.H. Rodriguez, R.V.A. Oliemans, Experimental study on oil-water flow in horizontal and slightly inclined pipes, International Journal of Multiphase Flow 32 (2006) 323-343.

[15] T.S. Raj, D.P. Chakrabarti, G. Das, Liquid-liquid stratified flow through horizontal conduits, Chemical Engineering and Technology 28 (2005) 899907.

[16] T.W.F. Russel, G.W. Hodgson, G.W. Govier, Horizontal pipeline flow of mixtures of oil and water, The Canadian Journal of Chemical Engineering 37 (1959) 917.

[17] T. Al-Wahaibi, P. Angeli, Transition between stratified and non-stratified horizontal oil-water flows. Part I- Stability analysis, Chemical Engineering Science 62 (2007) 2915-2928.

[18] A. Ullmann, M. Zamir, S. Gat, N. Brauner, Multi-holdups in co-current stratified flow in inclined tubes, International Journal Multiphase Flow 29 (2003) 15651581. 